\title{
MEIS1 and BTBD9: genetic association with restless leg syndrome in end stage renal disease
}

\author{
Barbara Schormair, ${ }^{1,2}$ Jens Plag, ${ }^{3}$ Maria Kaffe, ${ }^{1,2}$ Nadine Groß, ${ }^{4}$ Darina Czamara, ${ }^{5}$ \\ Walter Samtleben, ${ }^{6}$ Peter Lichtner, ${ }^{1,2}$ Andreas Ströhle, ${ }^{3}$ Ioannis Stefanidis, ${ }^{7}$ \\ Andreas Vainas, ${ }^{7}$ Efthimios Dardiotis, ${ }^{8}$ George K Sakkas, ${ }^{7}$ Christian Gieger, ${ }^{9}$ \\ Bertram Müller-Myhsok, ${ }^{4}$ Thomas Meitinger, ${ }^{1,2}$ Uwe Heemann, ${ }^{10}$ \\ Georgios M Hadjigeorgiou, ${ }^{8}$ Konrad Oexle, ${ }^{2}$ Juliane Winkelmann ${ }^{1,2,4}$
}

For numbered affiliations see end of article.

\section{Correspondence to}

Juliane Winkelmann, Klinik für Neurologie und Institut für Humangenetik, Klinikum rechts der Isar, Technische Universität München (TUM), Ismaninger Strasse 22, 81675 München, Germany; winkelmann@lrz.tumuenchen.de

$\mathrm{BS}$ and JP contributed equally

Received 2 December 2010 Revised 8 February 2011 Accepted 21 March 2011 Published Online First 14 May 2011

\section{(2) UNLOCKA}

This paper is freely available online under the BMJ Journals unlocked scheme, see http:// jmg.bmj.com/site/about/ unlocked.xhtml

\section{ABSTRACT}

Background Restless legs syndrome (RLS) is a sleep related movement disorder that occurs both in an idiopathic form and in symptomatic varieties. RLS is a frequent and distressing comorbidity in end stage renal disease (ESRD). For idiopathic RLS (iRLS), genetic risk factors have been identified, but their role in RLS in ESRD has not been investigated yet. Therefore, a case-control association study of these variants in ESRD patients was performed.

Methods The study genotyped 10 iRLS associated variants at four loci encompassing the genes MEIS1, BTBD9, MAP2K5/SKOR1, and PTPRD, in two independent case-control samples from Germany and Greece using multiplex PCR and MALDI-TOF (matrix assisted laser desorption/ionisation time-of-flight) mass spectrometry. Statistical analysis was performed as logistic regression with age and gender as covariates. For the combined analysis a Cochran-Mantel-Haenszel test was applied.

Results The study included 200 RLS-positive and 443 RLS-negative ESRD patients in the German sample, and 141 and 393 patients, respectively, in the Greek sample. In the German sample, variants in MEIS1 and BTBD9 were associated with RLS in ESRD $\left(P_{\text {nom }} \leq 0.004\right.$, ORs 1.52 and 1.55), whereas, in the Greek sample, there was a trend for association to MAP2K5/SKOR1 and BTBD9 $\left(P_{\text {nom }} \leq 0.08,0 R s 1.41\right.$ and 1.33). In the combined analysis including all samples, BTBD9 was associated after correction for multiple testing $\left(P_{\text {corrected }}=0.0013\right.$, OR 1.47).

Conclusions This is the first demonstration of a genetic influence on RLS in ESRD patients with BTBD9 being significantly associated. The extent of the genetic predisposition could vary between different subgroups of RLS in ESRD.

\section{INTRODUCTION}

Restless legs syndrome (RLS) in end stage renal disease (ESRD) is a common form of symptomatic RLS and is associated with increased mortality and reduced quality of life. ${ }^{1}$ The prevalence of RLS ranges between $18.4 \%^{2}$ and $45.8 \%{ }^{3}$ in ESRD patients of European descent. Both RLS in ESRD and idiopathic RLS (iRLS) are diagnosed based on the clinical presentation of four main symptoms. These are specified in the essential diagnostic criteria defined by the International RLS Study Group (IRLSSG) ${ }^{4}$ : (1) an urge to move the legs, usually accompanied by unpleasant sensations; (2) precipitation of symptoms by rest and inactivity; (3) symptom relief by movement; and (4) worsening appearance in the evening or at night. An abnormal increase in periodic limb movements in sleep (PLMS) further supports the diagnosis and is present in $80-89 \%$ of RLS patients. ${ }^{5}$

For iRLS, a relatively strong genetic contribution has been demonstrated. ${ }^{6}$ Genome-wide association studies (GWAS) in iRLS cases from Germany and Iceland identified variants at four loci encompassing the genes MEIS1, BTBD9, MAP2K5/SKOR1, and PTPRD. ${ }^{7-9}$ Replication studies in iRLS cases from the USA and Europe (Czech Republic, Austria, and Finland) confirmed the association of MEIS1 and BTBD9. The MAP2K5/SKOR1 locus was replicated in the European cases but showed only a trend for association in the US cases. ${ }^{10}{ }^{11}$ With regard to ESRD, association studies have identified more than 20 variants contributing to disease susceptibility. ${ }^{12}$ There is no overlap between these variants and the known iRLS associated variants.

The pathophysiology of RLS in ESRD remains to be elucidated. So far, comparing clinical and biochemical parameters, such as duration and frequency of dialysis treatment or various components of phosphate and iron metabolism, in RLSpositive and RLS-negative ESRD patients yielded ambiguous results. ${ }^{3}{ }^{13-18}$

If and to what extent the susceptibility to RLS in ESRD is influenced by a genetic predisposition is not known. Since RLS in ESRD and iRLS are characterised by the same key symptoms, they possibly share genetic risk factors. Accordingly, we investigated the iRLS associated variants ${ }^{7-9}$ in a case-control association study of ESRD patients from Germany and Greece.

\section{SUBJECTS AND METHODS}

\section{Study populations and recruitment procedures}

\section{Germany (GER)}

ESRD patients on maintenance haemodialysis were recruited between January 2005 and August 2008 in 16 dialysis centres in Munich and the surrounding region.

ESRD patients who agreed to participate in the study answered a self administered diagnostic 
questionnaire incorporating the four essential IRLSSG criteria. ${ }^{4} 19$ All patients who answered at least one question affirmatively were then examined by a clinician specialising in RLS (JP or NG) by face-to-face interview and classified as 'RLS-positive' or 'RLSuncertain' (if less than four diagnostic criteria were fulfilled) according to this interview. Patients who had answered all diagnostic questions negatively in the initial questionnaire were classified as 'RLS-negative' without a personal interview.

\section{Greece (GR)}

ESRD patients on maintenance haemodialysis were recruited between January 2007 and December 2009 in seven dialysis centres in central and northern Greece. In brief, patients were interviewed (first screening), using the four IRLSSG criteria, by a nephrologist (AV) or neurologist (ED) trained by RLS experts (GMH and IS). ${ }^{4} 20$ The diagnosis of RLS was confirmed in a subsequent personal interview conducted by an expert neurologist (GMH or IS).

In both populations, family history of RLS (defined as the proband's report of at least one relative of up to the third degree affected by RLS) was recorded for RLS-positive patients. Data on duration of dependence on dialysis and on weekly rate of dialysis was collected for all ESRD patients. In the German sample, age of onset of RLS was also recorded.

The study was approved by the respective local ethics committees in Germany and Greece. All patients were informed about the aims and protocol of the study. Written informed consent was obtained from all patients.

\section{SNP selection, genotyping, and quality control}

We genotyped 10 iRLS associated single nucleotide polymorphisms (SNPs) across the four genomic regions. ${ }^{7-9}$ Genotyping was performed according to the iPLEX Gold protocol using matrix assisted laser desorption/ionisation time-of-flight (MALDI-TOF) mass spectrometry (Sequenom, San Diego, California, USA). Assays were designed using AssayDesign 3.1.2.2 with the default parameters for the iPLEX Gold chemistry. Cleaned extension products were analysed by mass spectrometer (Bruker Daltronik, Bremen, Germany) and peaks were identified using SpectroTYPER RT 3.4.

Quality control criteria leading to exclusion of an SNP from further analysis were a call rate $<95 \%$, a minor allele frequency (MAF) $<5 \%$, and value of $\mathrm{p}<0.001$ for deviation from Hardy-Weinberg-Equilibrium (HWE) in controls. Furthermore, DNA samples with a call rate $<95 \%$ over all SNPs were excluded from the analysis.

\section{Statistical analysis}

Statistical analysis was performed using PLINK v1.07 ${ }^{21}$ for the SNP association tests and R 2.10.1 (http://www.r-project.org) for all other analyses. Statistical significance was defined at the $95 \%$ level $(p<0.05)$. Association of disease status and SNP allele count was tested using logistic regression, with age and gender as covariates. For the combined analysis of both populations, the sample was stratified based on the country of origin and a Cochran-Mantel-Haenszel test was applied. To correct for multiple testing, empirical $p$ values were generated by the $\max (\mathrm{T})$ permutation procedure implemented in PLINK v1.07 ( $n=10000)$.

Dialysis parameters and mean age were compared between cases and controls by means of a two-sided Student's t test. A $\chi^{2}$ test was utilised to compare gender ratios. Study power was calculated using the CATs power calculator, ${ }^{22}$ with settings of an additive genetic model, disease prevalence of 0.2 , and risk allele frequencies and ORs as estimated in previous studies. 7811

\section{RESULTS}

\section{Study populations}

In the German study, 737 of 1617 ESRD patients agreed to participate (45.6\%). Many ESRD patients had comorbidities such as dementia or depression and were not able to participate, leading to the relatively low response rate. According to the diagnostic questionnaire, 253 ESRD patients were considered 'potential RLS in ESRD' cases. Of these, 53 were subsequently excluded from the study (uncertain diagnosis: $n=44$; non-European descent: $n=6$; incomplete data: $n=3$ ). The final study population included 200 RLS-positive patients (prevalence of RLS in ESRD $31.1 \%$ ). Positive family history of RLS was reported by 38 of these patients (19\%), 133 (66.5\%) had a negative family history, and for 29 (14.5\%) there was no information available. Controls were selected from 484 RLS-negative ESRD patients. Of these, 41 were excluded from the study (nonEuropean descent: $n=13$, incomplete data: $n=28$ ), yielding a final control sample of 443 RLS-negative ESRD patients. Cases and controls did not differ significantly with regard to age, gender ratio, and the recorded dialysis parameters (table 1).

In the Greek study, 572 of 613 ESRD patients agreed to participate (93.3\%). According to the first screening, 162 ESRD patients were considered 'potential RLS in ESRD' cases. Of these, 21 were subsequently excluded from the study (uncertain diagnosis: $\mathrm{n}=15$; non-European descent: $\mathrm{n}=1$; incomplete data: $\mathrm{n}=5$ ), resulting in a case sample of 141 RLS-positive patients (prevalence of RLS in ESRD 26.4\%). Positive family history of RLS was reported by seven patients (4.9\%), 129 (91.5\%) had a negative family history, and for five (3.6\%) no information was available. Controls were selected from 410 RLS-negative ESRD patients. After excluding 17 patients due to incomplete data, 393 RLS-negative ESRD patients remained. Cases and controls had a significantly different mean age, but were similar in gender ratio and dialysis parameters (table 1 ).

Table 1 Demographic and dialysis data of final study population

\begin{tabular}{|c|c|c|c|c|c|c|c|}
\hline & \multicolumn{3}{|l|}{ GER } & \multicolumn{3}{|l|}{ GR } & \multirow{2}{*}{$\begin{array}{l}\text { GER vs GR } \\
\text { p Value }\end{array}$} \\
\hline & $\begin{array}{l}\text { RLS-positive ESRD } \\
\text { patients } n=200\end{array}$ & $\begin{array}{l}\text { RLS-negative ESRD } \\
\text { patients } n=443\end{array}$ & p Value & $\begin{array}{l}\text { RLS-positive ESRD } \\
\text { patients } n=141\end{array}$ & $\begin{array}{l}\text { RLS-negative ESRD } \\
\text { patients } n=393\end{array}$ & p Value & \\
\hline $\begin{array}{l}\text { Mean dialysis duration } \\
\text { (hours per week, mean } \pm S D \text { ) }\end{array}$ & $\begin{array}{l}13.6 \pm 2.2 \\
\text { (NA for } 42 \text { patients) }\end{array}$ & $\begin{array}{l}13.6 \pm 2.7 \\
\text { (NA for } 138 \text { patients) }\end{array}$ & 0.81 & $12.0 \pm 0.3$ & $11.9 \pm 0.4$ & 0.31 & $2.2 \times 10^{-10}$ \\
\hline $\begin{array}{l}\text { Mean dependence on dialysis } \\
\text { (months, mean } \pm \text { SD) }\end{array}$ & $\begin{array}{l}70.7 \pm 68.5 \\
\text { (NA for } 34 \text { patients) }\end{array}$ & $\begin{array}{l}60.7 \pm 62.2 \\
\text { (NA for } 105 \text { patients) }\end{array}$ & 0.11 & $45.2 \pm 41$ & $41.6 \pm 45.8$ & 0.9 & $8.1 \times 10^{-10}$ \\
\hline Age (years, mean $\pm S D$ ) & $64.8 \pm 12.5$ & $65 \pm 13.4$ & 0.9 & $60.3 \pm 12.4$ & $66 \pm 13.4$ & $5.4 \times 10^{-6}$ & 0.58 \\
\hline
\end{tabular}

Age and dialysis parameters were analysed by two-sided Student's t tests. Gender ratios were subjected to a $\chi^{2}$ test.

GER, German; GR, Greek; n, number; NA, not available; -, not applicable. 
Comparison of demographic data and dialysis parameters between the German and the Greek sample showed significant differences in the weekly rate of dialysis and the mean duration of dependence on dialysis, whereas mean age and gender ratios were similar (table 1).

\section{Association analysis}

The 10 selected SNPs passed quality control and were subjected to statistical analysis. A total of 43 individuals (22 in GER sample, 21 in GR sample) were excluded due to low genotyping quality. Analysis of the German sample (195 cases and 426 controls) revealed significant association to RLS in ESRD for variants in MEIS1 and BTBD9 (table 2). Within MEIS1, two of three SNPs were significantly associated after correction for multiple testing: $\mathrm{rs} 12469063\left(\mathrm{P}_{\text {nom }}=0.002, \mathrm{P}_{\text {corrected }}=0.013, \mathrm{OR}\right.$ $1.52)$ and rs2300478 $\left(\mathrm{P}_{\text {nom }}=0.004, \mathrm{P}_{\text {corrected }}=0.026, \mathrm{OR} 1.47\right)$. In $B T B D 9$, rs3923809 was associated $\left(\mathrm{P}_{\text {nom }}=0.001, \mathrm{P}_{\text {corrected }}=0.009\right.$, OR 1.56). For MAP2K5/SKOR 1 and PTPRD the nominal $p$ values ranged from 0.17 to 0.69 (table 2). In contrast, the Greek sample (138 cases, 375 controls) showed only nominal significance for a single SNP in MAP2K5/SKOR1 (rs3784709, $\mathrm{P}_{\text {nom }}=0.021$ ) and a trend of association for two further SNPs in MAP2K5/SKOR 1 and for rs3923809 in BTBD9 (table 2). In the combined analysis of all samples, stratified according to the country of origin, rs3923809 in BTBD9 and four SNPs in MAP2K5/SKOR1 showed nominal significance, but only rs3923809 remained significant after correction for multiple testing (table 2).

The statistical power of the German sample was higher than that of the Greek sample, owing to the larger sample size. For MEIS1, power in both samples was $\geq 90 \%$, for BTBD9 it was $85 \%$ in the German sample and $74 \%$ in the Greek sample. For the other loci, power was $<80 \%$ in both populations (table 2 ).

A subanalysis in the German sample with cases stratified according to their family history revealed a trend for differences in the size of the contribution of the associated loci to familial versus sporadic RLS in ESRD. Analysis of cases with a positive family history only $(n=38)$ revealed a significant association both with MEIS1 and BTBD9 (rs12469063, $\mathrm{P}_{\text {nom }}=0.003, \mathrm{P}_{\text {corrected }}=0.014$; rs2300478, $\quad P_{\text {nom }}=0.005, \quad P_{\text {corrected }}=0.023, \quad$ and rs3923809, $\left.\mathrm{P}_{\text {nom }}=0.006, \mathrm{P}_{\text {corrected }}=0.03\right)$. Using only cases with a negative family history $(n=133)$, the two loci showed nominally significant $p$ values (rs12469063, $P_{\text {nom }}=0.038, \quad P_{\text {corrected }}=0.224$; rs2300478, $P_{\text {nom }}=0.055, \quad P_{\text {corrected }}=0.306$, and rs3923809, $\left.\mathrm{P}_{\text {nom }}=0.025, \mathrm{P}_{\text {corrected }}=0.147\right)$. ORs differed for both groups but the $95 \%$ CIs overlapped: positive family history: MEIS1: 2.1 (1.29-3.39); BTBD9: OR 2.39 (95\% CI 1.28 to 1.87); negative family history: MEIS1: OR 1.38 (95\% CI 1.02 to 1.87); BTBD9: OR 1.42 (95\% CI 1.05 to 1.92$)$. The Greek sample did not contain enough cases with a positive family history $(n=7)$ to conduct a similar analysis.

\section{DISCUSSION}

It has long been known that idiopathic and symptomatic RLS share the same key symptoms and that iRLS susceptibility is subject to genetic influences. Here, we show that genetic predisposition also plays a role in RLS in ESRD and that at least some of the underlying risk variants are common to both iRLS and RLS in ESRD.

In the German sample, sequence variants in MEIS1 and $B T B D 9$ were clearly identified as genetic susceptibility factors for RLS in ESRD patients $\left(\mathrm{P}_{\text {corrected }} \leq 0.03\right)$. The effect size of these variants is within the same range as observed in iRLS studies of comparable sample size (ORs $s_{\text {RS in ESRD }} 1.47-1.55,95 \%$ CI 1.19 to 2.04; ORs iRLS $1.43-1.59,95 \%$ CI 1.12 to 2.2$).{ }^{10} 11$ This was

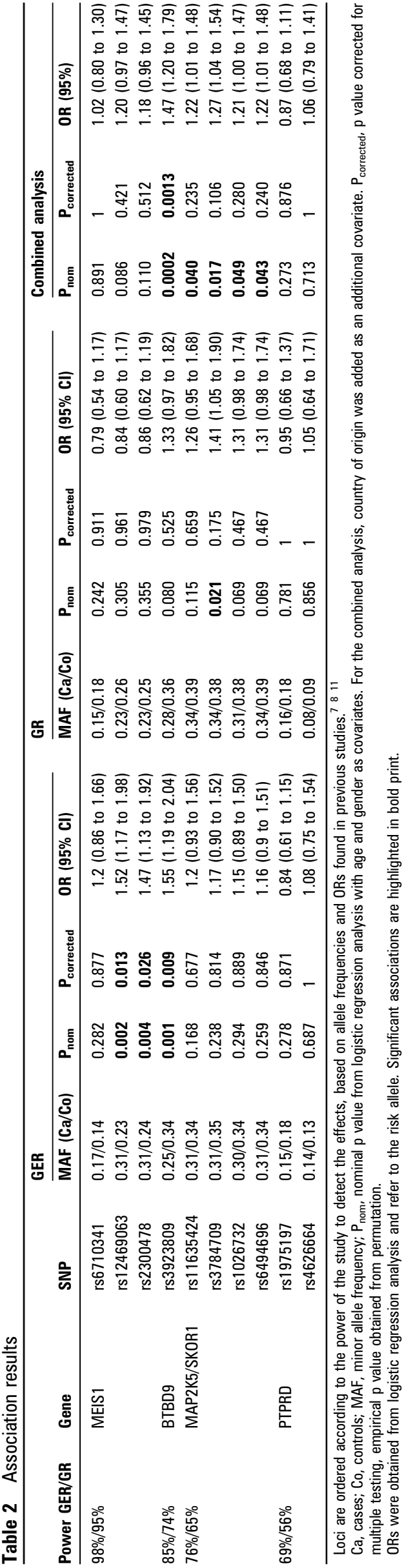


confirmed in an analysis using population based controls as the control group yielding similar ORs and CIs for the associated genes MEIS1 and BTBD9 (data not shown). However, the present data did not indicate a contribution of variants in MAP2K5/SKOR 1 and PTPRD to RLS in ESRD in the German sample. The absence of significant association to these loci may be due to the relatively small sample sizes in our study-that is, to the limited power.

Concerning the Greek sample, we could observe a trend for association to BTBD9 and MAP2K5/SKOR1. Several differences between both samples could account for the divergences between the German and the Greek results. (1) Sample sizes differed. (2) Greek ESRD patients were on dialysis for a significantly shorter time than the German patients and at a lower weekly rate (table 1). In several previous studies, the frequency of RLS in ESRD increased with the duration of dependence on dialysis. ${ }^{3}{ }^{13-18}$ It is possible, therefore, that some of the currently RLS-negative Greek ESRD patients will develop RLS in the future. Such false-negative controls would distort the association results. (3) The samples differed notably in the percentage of RLS cases with a positive family history (19\% in GER vs $5 \%$ in GR). The subanalysis based on family history of RLS in the German sample suggested a stronger contribution of the genetic risk factors in cases with a positive family history. This trend has also been observed in iRLS populations. ${ }^{10} 11$ The lower percentage of familial RLS could thus explain the weakened association signal for BTBD9 in the Greek sample. However, it has to be considered that the information on family history was obtained only by the proband's report, and was not confirmed in a direct personal interview of the relatives. Therefore, both falsenegative and false-positive classifications may have occurred. (4) For MEIS1, we see a sizeable difference in allele frequency between Greek and German RLS-positive ESRD patients (table 2), indicating that in the Greek population either MEIS1 is not an RLS risk factor or the causal variant in MEIS1 may not be in linkage disequilibrium with the variants under study.

Despite the differences in sample characteristics and individual association results, $B T B D 9$ shows a consistent trend for association in the separate as well as the combined samples. Previous analysis in iRLS has linked BTBD9 to the presence of PLMS, the motor component of RLS. ${ }^{9}$ Therefore, its association with RLS in ESRD is remarkable because motor symptoms seem to be more prominent in RLS in ESRD when compared to iRLS. $^{23} 24$

The prevalence of RLS in ESRD observed in our study $(31.1 \%$ in GER, $26.4 \%$ in GR) is in keeping with previous investigations, ${ }^{2}{ }^{14-18}$ and higher than that of RLS in the general population at the same age $\left(10 \%\right.$ in GER, 3.9\% in GR). ${ }^{20} 2526$ The prevalence of iRLS is substantially lower in Greece, while the prevalence of ESRD is quite similar with prevalence rates of $0.11 \%$ and $0.10 \%$ in Germany and Greece, respectively. ${ }^{27}$

The effect sizes of MEIS1 and BTBD9 in our study are of the same magnitude as in iRLS and, thus, do not account for the increased frequency of RLS in ESRD patients. It is likely that there are as yet undiscovered genetic, non-genetic, or non-shared environmental factors influencing the RLS phenotype. Our finding that only $5 \%$ (GR) to $19 \%$ (GER) of patients with RLS in ESRD reported a positive family history is in line with previous observations showing a lower frequency of familial RLS $(12 \%)^{28}$ in cases with RLS in ESRD compared to iRLS cases (30-92\%). ${ }^{6}$ The reduced familial clustering of RLS in ESRD patients could be interpreted as an indicator of a stronger influence of non-genetic factors in the aetiology of RLS in ESRD as compared to iRLS. Moreover, studies have shown that RLS symptoms are reduced after renal transplantation, ${ }^{29}$ suggesting that non-genetic factors such as reduced renal function and incomplete clearance of uraemic toxins during dialysis could have a major influence on the development of RLS in ESRD.

In conclusion, we were able to show a genetic contribution to susceptibility for RLS in ESRD. BTBD9 is significantly associated with RLS in ESRD. Our results suggest that the genetic influence might be stronger in the subgroup of RLS in ESRD patients with a positive family history. The study was limited to a subset of genes previously identified to be associated with iRLS. A GWAS using RLS-positive (cases) and RLS-negative (controls) ESRD patients might disclose further genetic risk variants for RLS in ESRD. All or some of these could-albeit not necessarily - also play a role in iRLS.

\section{Author affiliations}

${ }^{1}$ Institute of Human Genetics, Helmholtz Zentrum München - German Research Center for Environmental Health, Neuherberg, Germany

${ }^{2}$ Institute of Human Genetics, Technische Universität München, Munich, Germany ${ }^{3}$ Department of Psychiatry and Psychotherapy, Campus Charite Mitte, Charité Universitätsmedizin Berlin, Berlin, Germany

${ }^{4}$ Department of Neurology, Klinikum Rechts der Isar, Technische Universität München, Munich, Germany

${ }^{5}$ Max Planck Institute of Psychiatry, Munich, Germany

${ }^{6}$ Department of Internal Medicine, Nephrology Division, University of Munich - Klinikum Grosshadern, Munich, Germany

${ }^{7}$ Department of Nephrology, Faculty of Medicine, University of Thessaly, BIOPOLIS, Larissa, Greece

${ }^{8}$ Department of Neurology, Faculty of Medicine, University of Thessaly, BIOPOLIS, Larissa, Greece

${ }^{9}$ Institute of Epidemiology, Helmholtz Zentrum München - German Research Center for Environmental Health, Neuherberg, Germany

${ }^{10}$ Department of Nephrology, Klinikum Rechts der Isar, Technische Universität München, Munich, Germany

Acknowledgements We are grateful to all patients who participated in this study We also thank the Kuratorium für Dialyse und Nierentransplantation e.V. (KfH) dialysis centres KfH Nierenzentrum Ebersberg (Dr. med. Kathrin Stephanie Lange) KfH Nierenzentrum Freising (Dr. med. Monika Wildgruber), KfH Nierenzentrum Germering (Dr. med. Hermann Hacker), KfH Nierenzentrum Ingolstadt (Dr. med. Friedrich Josef Lazarus), KfH Nierenzentrum Miesbach (Dr. med. Daniela Anne Soreth-Rieke), KfH Nierenzentrum München Burggrafenstrasse (Dr. med. Gabriele Schätzle), KfH Nierenzentrum München Elsenheimer Strasse (PD Dr. med. Stephan Lederer), KfH Nierenzentrum München Isoldenstrasse (Prof. Dr. med. Johannes Mann), KfH Nierenzentrum München Seybothstrasse (Prof. Dr. med. Jürgen Scherberich), KfH Nierenzentrum Neuried (Prof. Dr. med. Walter Samtleben), KfH Nierenzentrum Oberschleissheim (Dr. med. Norbert Bockreiss), KfH Nierenzentrum Pfaffenhofen (Dr. med. Axel Witte), KfH Nierenzentrum Rosenheim (Dr. med. Andreas Thiele), KfH Nierenzentrum Straubing (Prof. Dr. med. Marianne HaagWeber), KfH Nierenzentrum Traunstein (Dr. med. Martin Gottsmann), and KfH Nierenzentrum Unterhaching (Dr. med. Klaus Hällfritzsch) for their help in conducting the study. We also thank the participating patients and dialysis centres in Greece.

Funding This study was supported in part (for GMH and ED) from University of Thessaly, Research Committee (Code 2845).

Competing interests WS has received lecture fees from Ortho Biotech, GE Health Care, Sanofi Aventis and Roche Pharma. TM, BMM, JW filed a patent regarding the publication Winkelmann et al 2007.

Ethics approval This study was conducted with the approval of the local ethics committees in Germany (Klinikum rechts der Isar, TU München) and in Greece (University of Thessaloniki)

Provenance and peer review Not commissioned; externally peer reviewed.

\section{REFERENCES}

1. Winkelman JW, Chertow GM, Lazarus JM. Restless legs syndrome in end-stage renal disease. Am J Kidney Dis 1996:28:372-8.

2. Merlino G, Piani A, Dolso P, Merlino G, Piani A, Dolso P, Adorati M, Cancelli I, Valente M, Gigli GL. Sleep disorders in patients with end-stage renal disease undergoing dialysis therapy. Nephrol Dial Transplant 2006;21:184-90.

3. Siddiqui S, Kavanagh D, Traynor J, Mak M, Deighan C, Geddes C. Risk factors for restless legs syndrome in dialysis patients. Nephron Clin Pract 2005;101:c155-60.

4. Allen RP, Picchietti D, Hening WA, Trenkwalder C, Walters AS, Montplaisir J. Restless legs syndrome: diagnostic criteria, special considerations, and epidemiology. 
A report from the restless legs syndrome diagnosis and epidemiology workshop at the National Institutes of Health. Sleep Med 2003;4:101-19.

5. Montplaisir J, Boucher S, Poirier G, Lavigne G, Lapierre 0, Lesperance P. Clinical, polysomnographic, and genetic characteristics of restless legs syndrome: a study of 133 patients diagnosed with new standard criteria. Mov Disord 1997;12:61-5.

6. Winkelmann J, Polo O, Provini F, Nevsimalova S, Kemlink D, Sonka K, Högl B, Poewe W, Stiasny-Kolster K, Oertel W, de Weerd A, Strambi LF, Zucconi M, Pramstaller PP, Arnulf I, Trenkwalder C, Klein C, Hadjigeorgiou GM, Happe S, Rye D, Montagna P. Genetics of restless legs syndrome (RLS): state-of-the-art and future directions. Mov Disord 2007;22(Suppl 18):S449-58.

7. Winkelmann J, Schormair B, Lichtner $P$, Ripke $S$, Xiong $L$, Jalilzadeh $S$, Fulda $S$, Pütz B, Eckstein G, Hauk S, Trenkwalder C, Zimprich A, Stiasny-Kolster K, Oertel W, Bachmann CG, Paulus W, Peglau I, Eisensehr I, Montplaisir J, Turecki G, Rouleau G, Gieger C, Illig T, Wichmann HE, Holsboer F, Müller-Myhsok B, Meitinger T. Genomewide association study of restless legs syndrome identifies common variants in three genomic regions. Nat Genet 2007;39:1000-6.

8. Schormair B, Kemlink D, Roeske D, Eckstein G, Xiong L, Lichtner P, Ripke S Trenkwalder C, Zimprich A, Stiasny-Kolster K, Oertel W, Bachmann CG, Paulus W, Högl B, Frauscher B, Gschliesser V, Poewe W, Peglau I, Vodicka P, Vávrová J, Sonka K, Nevsimalova S, Montplaisir J, Turecki G, Rouleau G, Gieger C, Illig T, Wichmann HE, Holsboer F, Müller-Myhsok B, Meitinger T, Winkelmann J. PTPRD (protein tyrosine phosphatase receptor type delta) is associated with restless legs syndrome. Nat Genet 2008:40:946-8.

9. Stefansson $\mathbf{H}$, Rye DB, Hicks A, Petursson $H$, Ingason A, Thorgeirsson TE, Palsson S, Sigmundsson T, Sigurdsson AP, Eiriksdottir I, Soebech E, Bliwise D, Beck JM, Rosen A, Waddy S, Trotti LM, Iranzo A, Thambisetty M, Hardarson GA, Kristjansson K, Gudmundsson LJ, Thorsteinsdottir U, Kong A, Gulcher JR, Gudbjartsson D, Stefansson K. A genetic risk factor for periodic limb movements in sleep. $N$ Engl J Med 2007;357:639-47.

10. Vilarino-Guell C, Farrer MJ, Lin SC. A genetic risk factor for periodic limb movements in sleep. $N$ Engl J Med 2008;358:425-7.

11. Kemlink D, Polo O, Frauscher B, Gschliesser V, Högl B, Poewe W, Vodicka P, Vavrova J, Sonka K, Nevsimalova S, Schormair B, Lichtner P, Silander K, Peltonen L, Gieger C, Wichmann HE, Zimprich A, Roeske D, Müller-Myhsok B, Meitinger T, Winkelmann $\mathrm{J}$. Replication of restless legs syndrome loci in three European populations. J Med Genet 2009:46:315-18.

12. O'Seaghdha CM, Fox CS. Genetics of chronic kidney disease. Nephron Clin Pract 2011;118:c55-63.

13. Collado-Seidel V, Kohnen R, Samtleben W, Hillebrand GF, Oertel WH, Trenkwalder C. Clinical and biochemical findings in uremic patients with and without restless legs syndrome. Am J Kidney Dis 1998;31:324-8.

14. Gigli GL, Adorati M, Dolso P, Piani A, Valente M, Brotini S, Budai R. Restless legs syndrome in end-stage renal disease. Sleep Med 2004;5:309-15.

15. Huiqi 0, Shan L, Mingcai 0 . Restless legs syndrome (RLS) in uremic patients is related to the frequency of hemodialysis sessions. Nephron 2000:86:540.
16. Takaki J, Nishi T, Nangaku M, Shimoyama H, Inada T, Matsuyama N, Kumano H, Kuboki T. Clinical and psychological aspects of restless legs syndrome in uremic patients on hemodialysis. Am J Kidney Dis 2003;41:833-9.

17. Araujo SM, de Bruin VM, Nepomuceno LA, Maximo ML, Daher Ede F, Correia Ferre $D P$, de Bruin PF. Restless legs syndrome in end-stage renal disease: clinical characteristics and associated comorbidities. Sleep Med 2010:11:785-90.

18. La Manna G, Pizza F, Persici E, Baraldi O, Comai G, Cappuccilli ML, Centofanti F, Carretta E, Plazzi G, Coli L, Montagna P, Stefoni S. Restless legs syndrome enhances cardiovascular risk and mortality in patients with end-stage kidney disease undergoing long-term haemodialysis treatment. Nephrol Dial Transplant 2011;26:1976-83.

19. Berger K, Luedemann J, Trenkwalder C, John U, Kessler C. Sex and the risk of restless legs syndrome in the general population. Arch Intern Med 2004;164:196-202.

20. Hadjigeorgiou GM, Stefanidis I, Dardiotis E, Aggellakis K, Sakkas GK, Xiromerisiou G, Konitsiotis S, Paterakis K, Poultsidi A, Tsimourtou V, Ralli S, Gourgoulianis K, Zintzaras E. Low RLS prevalence and awareness in central Greece: an epidemiological survey. Eur J Neurol 2007:14:1275-80.

21. Purcell S, Neale B, Todd-Brown K, Thomas L, Ferreira MA, Bender D, Maller J, Sklar P, de Bakker PI, Daly MJ, Sham PC. PLINK: a tool set for whole-genome association and population-based linkage analyses. Am J Hum Genet 2007:81:559-75

22. Skol AD, Scott LJ, Abecasis GR, Boehnke M. Joint analysis is more efficient than replication-based analysis for two-stage genome-wide association studies. Nat Genet 2006;38:209-13

23. Wetter TC, Stiasny K, Kohnen R, Oertel WH, Trenkwalder C. Polysomnographic sleep measures in patients with uremic and idiopathic restless legs syndrome. Mov Disord 1998;13:820-4

24. Enomoto M, Inoue $Y$, Namba K, Munezawa T, Matsuura M. Clinical characteristics of restless legs syndrome in end-stage renal failure and idiopathic RLS patients. Mov Disord 2008;23:811-16.

25. Rothdach AJ, Trenkwalder C, Haberstock J, Keil U, Berger K. Prevalence and risk factors of RLS in an elderly population: the MEMO study. Memory and Morbidity in Augsburg Elderly. Neurology 2000;54:1064-8.

26. Phillips B, Young T, Finn L, Asher K, Hening WA, Purvis C. Epidemiology of restless legs symptoms in adults. Arch Intern Med 2000;160:2137-41.

27. U S Renal Data System. USRDS 2009 Annual Data Report: Atlas of Chronic Kidney Disease and End-Stage Renal Disease in the United States. Bethesda, MD: National Institutes of Health, National Institute of Diabetes and Digestive and Kidney Diseases, 2009:350.

28. Winkelmann J, Wetter TC, Collado-Seidel V, Gasser T, Dichgans M, Yassouridis A Trenkwalder C. Clinical characteristics and frequency of the hereditary restless legs syndrome in a population of 300 patients. Sleep 2000;23:597-602.

29. Molnar MZ, Novak M, Ambrus C, Szeifert L, Kovacs A, Pap J, Remport A, Mucsi I. Restless legs syndrome in patients after renal transplantation. Am J Kidney Dis 2005:45:388-96 